\title{
CK2-targeting Synthetic Peptide CIGB-300
}

National Cancer Institute

\section{Source}

National Cancer Institute. CK2-targeting Synthetic Peptide CIGB-300. NCI Thesaurus.

Code C102849.

A synthetic peptide targeting the substrates of casein kinase 2 (CK2), with potential antineoplastic activity. Upon administration and nucleolar localization, CK2-targ eting synthetic peptide CIGB-300 binds to phosphoacceptor sites on the CK2 substrates, in particular the oncoprotein nucleophosmin (B23 or NPM1). This blocks the activation of B23 and induces apoptosis, thereby inhibiting tumor cell growth in susceptible tumor cells. CK2, a protein kinase often overexpressed in a variety of cancer cell types, appears to be correlated with malignant transformation, tumor growth and survival. Overexpression of B23 has been correlated with increased cellular growth and proliferation as well as inhibition of differentiation and apoptosis. 